\title{
Unmasking the Truth beneath the Beauty: why the supposed aesthetic judgements made in science may not be aesthetic at all.
}

\author{
Cain Todd, Department of Philosophy, Lancaster University, Lancaster LA1 4YG, U.K. \\ c.todd@lancaster.ac.uk
}

\begin{abstract}
In this paper I examine the status of putative aesthetic judgements in science and mathematics. I argue that if the judgements at issue are taken to be genuinely aesthetic they can be divided into two types, positing either a disjunction or connection between aesthetic and epistemic criteria in theory/proof assessment. I show that both types of claims face serious difficulties in explaining the purported role of aesthetic judgements in these areas. I claim that the best current explanation of this role, McAllister's 'aesthetic induction' model, fails to demonstrate that the judgements at issue are genuinely aesthetic. I argue that, in light of these considerations, there are strong reasons for suspecting that many, and perhaps all, of the supposedly aesthetic claims are not genuinely aesthetic at all but are in fact 'masked' epistemic assessments.
\end{abstract}

\section{Introduction}

It is well-known that scientists and mathematicians often make what appear to be prima facie aesthetic judgements, or aesthetic evaluations, of the theories and proofs which are their currency. Proofs and theories - and the parts of which they are constituted; postulated entities, metaphysical commitments, axioms and hypotheses - are frequently called 'elegant' or 'beautiful', 'clumsy' or 'ugly', and many of the criteria cited in support of such attributions seem to be equivalent to those often employed in the socalled 'paradigmatic' cases of aesthetic appraisal, namely those concerning works of art.

So we hear talk of the symmetry, simplicity, order, coherence, unity, elegance, harmony and so on which invoke the aesthetic appraisals. (Engler 1990, 24-33) Moreover, the aesthetic value of a theory or proof is often explicitly held to play an important, indeed sometimes fundamental role both in their 'discovery' or 'formulation', as well as in their overall assessment and justification, and this appears to be no merely whimsical fancy indulged by a few eccentrics and renegades; many of the greatest luminaries in science and mathematics, particularly of the last century, have held such views, including Bohr, Dirac, Einstein, Heisenberg, Yang, Poincaré, Polkinghorne and Hardy. (McAllister 1996, 2005; Hardy 1940; Penrose 1974) 
The main question I want to consider in this paper is whether the apparent aesthetic judgements of proofs and theories made by practitioners in science and mathematics should be taken at face value, or whether there are good reasons to doubt that their appraisals - and, hence, the nature of their appreciation - are really aesthetic at all. ${ }^{1}$ It will be seen that the difficulties in answering this question go deeper than they might initially appear, right to the heart of what we mean by 'aesthetic' and how we draw the distinction between aesthetic and non-aesthetic; but partly also to the heart of what we mean by 'epistemic'. ${ }^{2}$ Determining how catholic we ought to be in extending the territory of the aesthetic in light of our findings thus has important implications not just for philosophical aesthetics, but also for the philosophy of science. It is thus surprising that so little has been written on this issue within the latter field, and even less in the former. ${ }^{3}$

That aesthetic judgements and the evaluation of scientific theories are odd bedfellows, and their conjunction a just object of suspicion, will be familiar to many philosophers of science. Of course some positions happily manage to incorporate aesthetic factors in scientific procedure, but generally at the expense of what their opponents see as one of the foundation pillars of scientific enterprise, its rationality. ${ }^{4}$ According to what is known as the 'rational model' of science, appeals to aesthetic factors in theory assessment look to be entirely out of place. This model incorporates the fundamental idea that theories must possess the property of 'empirical adequacy' and be evaluated according to what James McAllister calls the 'logico-empirical model' of theory assessment. The model thus prescribes certain criteria which determine empirical adequacy and hence the

\footnotetext{
${ }^{1}$ Although I am concerned with aesthetic judgements in both mathematics and science, for reasons of space I shall talk primarily of the physical sciences whose theories are typically expressed in mathematical formulae, rather than proofs in pure mathematics. Where differences are important I will make some remarks about the latter based on the conclusions reached regarding the former, but many of the conclusions and problems are, I shall suggest, common to both areas. On the relationship between mathematics and physical science see Engler (1990), and McAllister (1996), 59. There are also, of course, important differences between pure and applied mathematics to bear in mind, and perhaps also between the physical and biological sciences, though I shall have little to say about the latter. It should also be noted that I am concerned here only with aesthetic appraisals of theories and proofs as these seem to me to be the most problematic and most central cases. Thus I shall not be concerned with aesthetic judgements of phenomena viewed in light of some theory, nor with aesthetic appraisals of representations of theories or proofs. See Jardine (1991), 209ff.; McAllister (1996), 24ff.; Penrose (1974), 267; Gowers (2002), $35 \mathrm{ff}$. ${ }^{2}$ It should be noted that I remain neutral on the question of whether science aims or should aim at truth, and although for the sake of shorthand I shall speak of the relationship between beauty and 'truth', one can read for 'truth' epistemic or empirical adequacy.

${ }^{3}$ In so far as McAllister's account fails to address this question adequately, I argue that to this extent the general plausibility of his account is weakened, as I discuss below.

${ }^{4}$ It is unfortunately beyond the scope of this paper to deal with these theories here.
} 
principles governing rational theory choice. McAllister lists these as follows: consistency with extant empirical data; novel prediction; consistency with current well-corroborated theories; explanatory power; empirical content; internal consistency. In light of this model it is at best mysterious how aesthetic judgements could interact with empirical factors in theory assessment, but at worst it looks like appeals to aesthetic criteria are simply irrational and to be treated with scepticism. (McAllister 1996, 9ff.)

In fact, there are two different forms such scepticism might take which are not often carefully distinguished. The first, weaker form, concerns the problematic role of aesthetic criteria in theory choice and theory assessment, casting doubt on many of the claims of scientists that aesthetic factors do play any important role in these procedures. If the claims at issue are taken at face value and held to be genuinely aesthetic, it is necessary to give some account of the role of aesthetic judgements in scientific practice, specifically by explaining their relationship to the central value of scientific theories, truth or empirical adequacy. However, I shall show that all such claims face grave difficulties, leading to a stronger sceptical line which holds not merely that aesthetic judgements are simply irrational or cannot play the genuine role in theory assessments that many prominent scientists and some philosophers seem to imply, but that they are not genuinely aesthetic at all.

Although the former problem has been much discussed, the issue of the aesthetic nature of the claims themselves has not received the attention that it deserves. (See Engler 1990; Kivy 1991; Zangwill 2001, 140-43) Naturally, if there are genuine reasons to doubt that the various claims at issue are aesthetic in the first place and cannot simply be taken at face value, then no further explanation will be required to make sense of the puzzling relationship between aesthetic and epistemic factors in theory assessment.

For this reason alone, the possibility that the claims at issue are not genuinely aesthetic should be taken seriously, and I shall argue in what follows that there are stronger reasons than hitherto suspected for doing so. Given the fundamental aims and functions of scientific theories and mathematical proofs, the properties generally cited as aesthetic are in fact more plausibly thought of as being essentially epistemic in function, insofar as they possess primarily epistemic value. Moreover, there is a systematic failure to provide 
any adequate account of what distinguishes aesthetic from epistemic criteria of assessment and evaluation that might undercut this line of argument.

It is important to realise that this scepticism about the aesthetic claims made by scientists and mathematicians can be motivated not only by different accounts of the nature of science, but also by certain specific conceptions of the aesthetic, in particular by the idea that aesthetic appreciation is disinterested..$^{5}$ Although I shall briefly discuss this notion, however, there is no need to examine or defend it in any depth because I think that strong enough philosophical doubts arise simply from consideration of the nature of the claims made, along with the general absence of adequate discussion of aesthetic criteria in this area. $^{6}$

It should be noted, however, that although I take my argument to provide strong reasons for casting doubt on the aesthetic nature of at least many of the claims made in mathematics and science, I do not claim to have proved the impossibility of some or even all of them being aesthetic. Rather, I claim merely that, in light of the sceptical arguments I provide, the burden of proof lies on those who would resist such scepticism and that part of their task, in addition to countering the arguments outlined, is to give an adequate theory of aesthetic value, appreciation, or properties that, on the one hand, distinguishes aesthetic assessments vis-à-vis epistemic assessments, and on the other hand, allows us to see how theories and proofs might fit the general contours of more paradigmatic examples of objects of aesthetic appreciation, such as artworks and natural objects. In conclusion, I make some brief suggestions as to how this challenge might be met and avenues for further research.

\footnotetext{
${ }^{5}$ Another approach is offered by Nick Zangwill (2001) who argues for the sensory-dependence of aesthetic properties based upon a formalist conception of such properties which disallows abstract entities like proofs and theories. There is no space here to discuss Zangwill's account in detail, but I think the sensorydependence thesis is unconvincing and positive arguments for it are in short supply. Zangwill himself defends it by focusing primarily on how apparently non-sensory cases of aesthetic appreciation, such as those involved in the pictorial meaning of paintings, and the content of literature, can be made to conform to the thesis. (See especially ch. 8). Whether the particular arguments he puts forward are successful or not, it is difficult to see how such a strategy could by itself possibly convince anyone who simply denied the sensory-dependence thesis and saw no difficulty in holding that abstract entities could be aesthetically appreciated. See McAllister (1996), 28-9 for discussion of the problem of perceiving the properties of abstract entities.

${ }^{6}$ A dependence on certain conceptions of the aesthetic that are open to dispute weakens the force of Zangwill's otherwise often ingenious arguments for more or less the same conclusion I uphold.
} 


\section{The Claims: conjunctions and disjunctions}

There is a great deal of overlap, conflict and ambiguity interwoven amongst the myriad different 'aesthetic' statements typically made by both mathematicians and scientists, which by itself should serve to raise some suspicion about the nature of these claims. (For examples see McAllister 1996; Osborne 1984; Engler 1990; Kivy 1991) But if for the moment we accept that such statements are genuine expressions of aesthetic value and appreciation, we can detect two possible positions concerning the relationship between the aesthetic and epistemic assessment of theories (and proofs): either there is held to be some sort of important connection or conjunction between them - or to put it briefly, between beauty and truth - or some sort of disjunction between them. Both conjunctive and disjunctive claims can be cashed out in various ways.

\section{a) Conjunctive claims}

To turn first to the conjunctive statements, there is a great deal of evidence to suggest that aesthetic judgements are thought to be importantly connected to empirical concerns in theory formulation and assessment, as the listed statements and the actual practice of scientists show. Indeed there seems to be a prevailing view that beauty is somehow linked with truth, perhaps as a sign of it. (See the many examples given in Kivy 1991; Engler 1990; Osborne 1984; McAllister 1996)

This belief generally consists in holding that aesthetic factors play some role in theory choice. Often it is claimed that this role consists merely in deciding between theories which on empirical grounds are perfectly equal. Aesthetic factors are, if you like, reduced to mere 'tie-breakers' premised on personal preference. When two theories or proofs exhibit equally good empirical adequacy or validity - that is, cases in which the choice among competing theories or proofs is underdetermined by the application of logicoempirical evaluative criteria - the choice between them can be made with regard to their relative aesthetic merits i.e. the more beautiful or aesthetically pleasing one is, or ought to be, usually adopted. (McAllister 1991) 
However, there are also stronger claims which suggest that a theory, if beautiful, can be accepted even in lieu of supporting empirical factors. (McAllister 1996, 16-17 and ch. 6) For example, Polkinghorne claimed that: 'It is a recognized technique in elementary particle physics to seek theories which are compact and mathematically beautiful, in the expectation that they will then prove to be the ones realized in nature.' (Osborne 1984, 29) While Chandrasekhar held that: 'We have evidence...that a theory developed by a scientist, with an exceptionally well-developed aesthetically sensibility, can turn out to be true even if, at the time of its formulation, it appeared not to be so.' (Kivy 1991, 190).

In other words, the idea is that a theory may be held to be true or likely to be true merely because of its aesthetic appeal without prior confirmation from empirical data. But how can this be? How could aesthetic factors be indicative of the empirical adequacy or truth of a theory?

Many scientists and mathematicians seem to think that theories and proofs are beautiful because they accurately describe or reflect the beauty of the world. Unfortunately, as enticing as this metaphysical faith might be, and as plausible as it no doubt is as an explanation of one key motivation for doing science in the first place, without independent justification for this metaphysical picture, there is clearly some danger of circularity in holding that a theory is beautiful on the grounds that it accurately represents, say, nature's beauty. For in many cases our belief in the aesthetic properties of the latter are only attained through the former. (McAllister 1996, 98-100)

A more plausible reason for linking truth and beauty, however, is simply to count the relevant aesthetic judgements as an aspect of empirical judgements, or vice versa. There are at least two such 'reductive' views available here. The first 'amounts to the claim that whether scientists attribute aesthetic value to a theory is determined entirely by its degree of empirical success...a scientist takes aesthetic pleasure in a theory when he or she recognizes and approves of the theory's empirical properties...' (McAllister 1996, 67) The second, more radical view, is that propounded by Peter Kivy (1991), who argues essentially for an equivalence between aesthetic and epistemic criteria. Rather than aesthetic pleasure being merely a reaction to empirical success, empirical success just is itself an aesthetic virtue. 
There are two main difficulties with the first view. On the one hand, it fails to explain many of the stated beliefs of scientists that one can prejudge empirical success by appealing to independent aesthetic criteria in the actual procedure of theory assessment, either as a tie-breaker or in the absence of empirical confirmation. Despite appearances to the contrary, empirical success on this view thus remains the sole criterion of theory assessment. (McAllister 1996, 68-9) On the other hand, it is unclear what then makes such pleasure aesthetic in the first place. How are we to demarcate this supposedly aesthetic pleasure from mere intellectual or practical satisfaction in the theory's success? After all, this is the prime function of scientific theories.

Clearly, scientists often employ aesthetic terms to appraise such things as the accuracy of empirical data, and more generally people often use aesthetic terms to express satisfaction at any outcome that promotes their interests. But what justification is there for thinking this is anything but a pseudo-aesthetic use of the vocabulary? (McAllister 1996, 36)

A great part of the problem here, evidently, is that discussions in this area rarely cite any identifying criteria of aesthetic interest or judgement, other than to point to the presence in statements of terms like 'beautiful' and 'elegant'; but this merely begs the question at issue. For given the essential epistemic function of science and mathematics many of the claims for the important role of supposedly aesthetic judgements look counterintuitive or mysterious. How could a sense of the beautiful, qua aesthetic property, be indicative of the truth/epistemic adequacy (of some theory), qua epistemic property?

At best, some positive account of the relation between epistemic and aesthetic criteria is needed, but as these are not generally forthcoming one must, I think, be at least initially suspicious that such claims are simply conflating aesthetic and epistemic criteria of assessment. In light of such suspicions, coupled with the problems posed by aesthetic judgements for rational theory choice, I suggest that there is a burden on defenders of the claims to provide clear evidence, in the form of distinguishing criteria, that the supposed pleasure expressed is genuinely aesthetic. As we shall see, attempts to discharge this burden have hitherto been inadequate. 
In respect of the second 'reductive' view, Kivy argues for an equivalence between aesthetic and epistemic criteria because, he claims, science ought to be considered as a representational art, in the sense that successful representation is a central aesthetic value: 'The beauty of theoretical science is the beauty of nature where science represents nature truly and beautifully.'(Kivy 1991, 193) Kivy himself freely admits that his position assumes a 'realistic interpretation of the scientific enterprise', (193) but more problematic is his assumption that there is a straightforward analogy between art and science in this regard. After all, it might be thought that art aims at beauty for its own sake, and it is the way in which something is represented (realistically) that counts aesthetically, not just the bare fact that it is realistic.

Science, on the other hand, just aims to get it right, and hence we are back with the problem of distinguishing intellectual from aesthetic pleasure. Is scientific success itself an aesthetic virtue? Indeed, it seems rather that what counts as 'representational success' in art and science are utterly different kinds of things, as the aim of scientific representation just is to get it right, and whether or not we also appreciate the 'getting it right' aesthetically is an additional matter.

Both of these reductive views, moreover, face adverse empirical evidence in the form of claims that aesthetic criteria can act as an independent factor in theory assessment. (McAllister 1996, 68-9) In other words, they assert too close a connection between truth and beauty, reducing the aesthetic to the epistemic or vice versa, thereby leaving it mysterious how we are to explain the differences and interaction between aesthetic and empirical criteria.

\section{b) Disjunctive claims}

There are at least two ways of cashing out the disjunctive claims, both of which also face problems vis-à-vis the rational model of science outlined earlier. The first type of disjunction amounts to the idea that aesthetic preferences can overrule empirical criteria in theory choice, and can be summed up in the claim: 'Beauty is more important than truth'. Dirac, for instance, asserted that: 'it is more important to have beauty in one's equations than to have them fit experiment.' (Engler 1990, 24). 
The credibility of such a statement, however, can be quickly discounted, for it is simply implausible to think that beauty might be more important than empirical adequacy in evaluating theories, qua theories, for this simply ignores their primary function, namely, conforming to the relevant norms of empirical adequacy. It thus seems difficult to imagine anybody really, consistently, asserting such a belief and yet continuing to practice science as normal.

In any case, the second type of disjunctive statement provides a prima facie more plausible view of the relationship (or rather lack thereof) between truth and beauty in theory assessment: 'Beauty is indifferent to truth'. This expresses the idea that we are able, in some sense, to consider a theory from an aesthetic point of view, without regard to its truth. One way of cashing this out has been to appeal to the idea that aesthetic appreciation is disinterested.

The concept of disinterestedness has been a persistent one in philosophical aesthetics ever since Kant, and has acquired two main aspects which make philosophers immediately suspicious of the aesthetic claims of scientists. The first is the idea that aesthetic judgements are unconcerned with truth and utilitarian ends, they must not be based on cognitive interest in attaining knowledge about something nor with assessing an object in relation to some purpose which it serves. These thoughts give rise to the second aspect, encapsulated in the idea that aesthetic appreciation concerns taking disinterested pleasure in some object for its own sake, without regard to ulterior purposes or the satisfaction of further, extraneous desires, such as cognitive understanding or sensual gratification. In this way, the aesthetic and empirical/epistemic evaluations of a theory or proof are completely independent of one another. Their aesthetic value bears no relation to their empirical/epistemic worth or utility. (Stolnitz, 1961; McAllister 1991, 1996, 61ff.)

Whether or not we ought to adopt the criterion of disinterest to demarcate the aesthetic, however, the disjunctive statements on the role of aesthetic judgements in theory assessment seem to entail that a theory may be beautiful but not true and, conversely, true but not beautiful. However, given the essentially truth-functional nature of scientific theories and mathematical proofs, it is difficult to make sense of the claim that we can 
readily divorce aesthetic judgement from epistemic concerns. Truth and empirical adequacy are not simply additional, accidental goals of science and mathematics but their essential functions. Theories are designed both in accord with and in order to conform to certain logico-empirical criteria. The essential function of mathematical proofs is to demonstrate the truth of theorems by according with the rules and axioms of mathematics.

So, the claim that theories and proofs may be true but not beautiful seems to be philosophically unproblematic, but what could it mean to appreciate a theory or proof for its own sake, regardless of whether it is true or not, given that a theory or proof just is inherently asserting some mathematical truth or epistemic fact to obtain? Could a theory really be beautiful but not true, given the norms of scientific practice? ${ }^{7}$

Providing an answer to this might look initially to be, at least partly, an empirical matter, but it must be remembered that it is the nature of the empirical evidence itself - the actual statements of mathematicians and scientists - that is at issue, and in addition to being strongly counterintuitive the bulk of evidence from the history of science appears to suggest a general belief that it could not. ( McAllister 1996) Indeed, where there do seem to be cases of theories that are claimed to be beautiful while acknowledged not to be true, or vice versa, it has been noted, by Nick Zangwill (2001) and McAllister (1996), that as well as being in the minority, such theories and proofs have at least properties which usually contribute towards fulfilling their primary functions. That is to say, a 'theory, while not itself enjoying empirical success, may have properties similar to those of other theories that have been empirically successful.' (McAllister 1996, 66) ${ }^{8}$

\footnotetext{
${ }^{7}$ For a fuller discussion of this issue see Zangwill (2001), 141-2. Zangwill's own position emerges out of his own developed theory of aesthetic formalism which, combined with the thesis of sensory-dependence, leads him to posit that the application of aesthetic terms to abstract objects, such as theories, proofs, and chess moves must be metaphorical. The further appeal to purposes and function relies rather on the idea that aesthetic assessment is simply out of place in such areas due to the fact that there can be no disjunction between truth and beauty given the nature of the objects at issue.

${ }^{8}$ I think McAllister's account here is perfectly plausible but, for reasons I am about to discuss, there are serious suspicions that the properties at issue in such claims, and which he discusses, are not aesthetic, as he holds, but epistemic. Indeed, cases such as this, where theories are held to be true but not beautiful and vice versa, actually, I think, support these suspicions. See below, section 3 .
} 
What are these properties? It turns out that many of them are the very properties generally invoked by scientists and mathematicians to support their supposed aesthetic judgements, for they appear to be the same as those cited in paradigmatic cases of the aesthetic: 'symmetry, simplicity, order, unity, coherence, elegance, harmony'. (Kivy 1991, 185; Engler 1990) As we shall see (section 3 below) however, far from confirming the aesthetic value of theories regardless of their epistemic virtues, there are strong reasons to doubt that such properties are aesthetic at all, thus confirming the suspicion that theories cannot be beautiful that do not have properties indicative of truth. We shall examine this further below, but even if these reasons themselves were rejected, some account would still be owed to us of what makes the relevant theories or their properties aesthetic irrespective of whether they are epistemically adequate.

Let us quickly take stock of the dilemma to which we seem to have been led by taking the claims at face value as being genuine expressions of aesthetic judgement: they seem either to posit an important connection between aesthetic and epistemic factors in theory assessment, or to hold in contrast that they are essentially unconnected. In the case of the former, it is difficult to see what independent role aesthetic factors could play in theory assessment, or indeed what the difference between aesthetic and empirical criteria of assessment actually is, given the reductive views which such a connection seems to yield. In the case of the disjunctive claims, problems also surround the mysterious role that aesthetic factors could play in theory assessment, particularly in respect of the problematic idea that theories could somehow be beautiful but not true.

These problems arise from considerations concerning a) the primary truth-functional or epistemic nature of scientific theories and mathematical proofs, and b) the failure to provide distinguishing characteristics of aesthetic and epistemic criteria and judgements. I have also hinted that the properties cited as evidence of aesthetic interest in fact point towards an essentially epistemic function, although we have yet to examine this in detail. Given that we have reached this point by taking the various claims at face value, as genuine expressions of aesthetic judgement, I therefore suggest that this casts some prima facie suspicion on the aesthetic nature of the claims themselves.

\section{McAllister's Aesthetic Induction}


Faced with the dilemma of strongly conflicting empirical evidence supporting opposing types of statements - disjunctive and conjunctive - McAllister (1996) provides the most comprehensive attempt to defend the rational model of science with respect to aesthetic criteria of theory assessment. He does so by developing a highly original and sophisticated position that attempts to account for the connection between aesthetic and epistemic criteria, without merely reducing the one to the other.

As his impressive study of the history of science demonstrates, there is a great deal of evidence to suggest that aesthetic claims are not independent of empirical concerns in theory formation and assessment, as many of the statements and the actual practice of scientists show. Indeed, as noted above, there seems to be a general prevailing view that beauty is somehow linked with truth. McAllister argues that there may well be - but not necessarily are - aesthetic criteria for recognizing empirical truths but which are nevertheless independent of empirical judgement. (McAllister 1996, 77-92 and ch. 12) He calls his position the 'aesthetic induction':

'When examining the empirical record of theories in their discipline, scientists attach to each aesthetic property a weighting roughly proportional to the degree of empirical adequacy that they attribute to theories exhibiting that property. The table of weightings constructed in this way constitutes the scientist's aesthetic canon, used thereafter to evaluate theories in their discipline.'(203)

McAllister holds that aesthetic judgements are judgements which attribute value to entities rather than describe any intrinsic properties of them. Focussing on beauty, he outlines a projectivist theory of aesthetic value in which value does not reside in the world intrinsically but is projected onto the world by valuers, amounting to the claim: 'we cannot fully describe a scientific theory's aesthetic value without referring to the effect of properties of that theory on scientists or other observers.'(31; see also ch. 12)

McAllister claims then that such projection must depend in part on the object's intrinsic properties, leading him to hold that aesthetic properties 'are those properties intrinsic to an object that evoke the aesthetic response of observers to that object, and, more specifically, contribute to determine whether observers project beauty into that object.' (32) The argument of the book is then essentially that the particular properties which a scientist or scientific community picks out as beautiful are a consequence of this 
individual or community subscribing to particular aesthetic criteria, the class of which constitutes that community's 'aesthetic canon'. (33-4; see also ch. 3) These properties and aesthetic criteria are not of a uniform aesthetic value but can be given various 'weightings' which are important when choosing between theories with different aesthetic properties. (chs. 2-6)

Various criticisms may be made of McAllister's overall theory of aesthetic induction, and as he himself acknowledges the main elements of his view of aesthetic judgement are all subject to dispute. However, I want to focus here on the more fundamental question of what makes the induction aesthetic in the first place.

On the view just outlined, the location of aesthetic properties depends on what counts as an aesthetic response. As David Davies (1998) notes, McAllister offers no comprehensive account of this but instead relies on two criteria for recognizing which properties are, on his definition, aesthetic. The first is this: a property of a theory is an 'aesthetic property if scientists in the relevant disciplines react to it publicly as aesthetic, for example by declaring that they attach aesthetic value to it, by citing it in an act of theory evaluation that they describe as aesthetic, or by applying to it standard terms of aesthetic appreciation, such as "beautiful", "elegant", "pleasing”, or "ugly"”. (36)

Now McAllister himself is quick to note that this reliance on the claims and acts of scientists themselves is open to the objection that it is hardly a failsafe method for identifying genuine aesthetic judgements, since people sometimes use aesthetic terms to express non-aesthetic judgements of entities. As noted above, scientists often employ aesthetic terms to appraise such things as the accuracy of empirical data, and more generally people often 'experience satisfaction at any outcome that promotes their interests, and sometimes they express this emotion in a pseudo-aesthetic vocabulary.'(36)

Nonetheless, he is content to rely on a principle of charity of interpretation in most cases of scientists' aesthetic judgements. Yet, given the suspicions we have already raised, this act of charity is problematic, particularly in lieu of any detailed account of what makes a response aesthetic. This problem is compounded by the implausibility of his second criterion for distinguishing aesthetic claims: 
'a property is aesthetic if, in virtue of possessing that property, a scientific theory is liable to strike beholders as having a high degree of aptness. The justification of this criterion is that, in many philosophies of art, the beauty of an object is explicated as its aptness or the aptness of its elements.' (37)

Now regardless of the importance of aptness in art, aptness by itself is surely not an aesthetic property. (Davies 1998, 28) It might be apt that a villain received his just desserts, but there is clearly nothing particularly aesthetic about this. As with most terms used aesthetically - aside from those special few whose primary function seems to be to express aesthetic interest, such as 'beauty', 'ugly', 'elegant', but note, not 'pleasure' - it is the context of use that determines whether they are being used to signify aesthetic interest or value, or not, and this McAllister and others generally fail to notice. After all, the simplicity of an idea, or a meal, is not necessarily the same as the aesthetic virtue of simplicity which a critic might use to express his aesthetic pleasure in looking at a Mondrian canvas. Even if the use of the former might not always be purely descriptive and evaluatively neutral, the latter qua aesthetic will (arguably) always be partly evaluative.

So in order to determine whether aptness as used in the evaluation of scientific theories is an aesthetic criterion depends on whether we think 'apt' is being applied aesthetically, or whether instead it simply signals, say, pleasure in the accuracy of the data, the conformity of hypothesis and observation, and so on. But on McAllister's view how is this to be decided other than by one of the two criteria in play? Problematically, it is the criterion of aptness which seems to directly determine some of the properties that McAllister then goes on to list as those properties of theories primarily responsible for evoking aesthetic responses - the aesthetic properties of theories that 'have had the greatest influence on scientists in history'.(39)

McAllister cites five 'classes' of aesthetic properties of theories: forms of symmetry and simplicity; visualizable structures and mechanisms; invocation of a model; metaphysical allegiance. (ch.3) The reasoning underlying the last two is unconvincing. Invocation of a familiar model is supposed to be an aesthetic property because 'the discovery that a theory lends itself to interpretation through an analogy of a favoured kind yields aesthetic 
satisfaction'. (48) Yet as Davies rightly points out, such pleasure or satisfaction looks to be of a more general kind of pleasure concerning our ability to apprehend or make sense of something rather than being specifically aesthetic. (Davies 1998, 28) It is certainly not readily distinguished as aesthetic by the formulation of any clear aesthetic criteria, such as the notion of disinterestedness provides.

Similarly, metaphysical allegiance is, according to McAllister, an aesthetic property because, firstly, 'a beholder who perceives an accord between the claims of a given scientific theory and his or her metaphysical commitments is likely to experience a sense of aptness.'(55) But again, it is obvious that this kind of aptness need not refer to an aesthetic property. Oddly, Davies leaves unchallenged the claims for simplicity and symmetry, but there are perhaps stronger reasons still for being sceptical about these, reasons that go the very heart of McAllister's project.

\section{Epistemic Criteria and Functionality}

As Kivy notes, the criteria generally invoked by scientists to support their supposed aesthetic judgements appear to be the same as those cited in clearer cases of the aesthetic: 'symmetry, simplicity, order, unity, coherence, elegance, harmony'. (Kivy 1991, 185; see also Engler 1990.) Yet, while Kivy himself sees no problem with this, I contend that these very criteria cast two doubts on their claim to be genuinely aesthetic.

First, the vocabulary of aesthetic appraisal employed in mathematics and science is relatively impoverished compared with the rich repertoire used in relation to art. Although we use 'elegant' and 'pretty', 'neat' and 'beautiful', and their contrasting properties of 'clumsy', 'dull', 'uninspired' and so on, we do not, as Ron Harre (1958) pointed out, use 'charming', 'delightful', 'lovely', 'handsome', 'sublime'. Second, and more importantly, the features cited tend to be equally criteria of truth or epistemic and empirical adequacy. They apparently overlap, in science, with many of the clearly nonaesthetic properties that are used to determine the epistemic strength of theories; and they overlap in pure maths with some of the criteria for judging proofs as valid or adequate. (Osborne 1984; Engler 1990; Penrose 1974; Gowers 2002; Hardy 1940). 
Given the suspicious overlap, particularly in light of the difficulties faced by both conjunctive and disjunctive claims, we must ask: how can we be sure that when scientists appeal to the simplicity and symmetry of theories that they are expressing aesthetic pleasure, as opposed to, say, intellectual pleasure in empirical success or the satisfaction of their own practical interests? How do we decide when a term is being used aesthetically and when not, keeping in mind that to appeal to scientific theories as nonaesthetic would simply be to beg the question? Clearly the criteria at issue will not be functioning aesthetically if they are in fact reducible to 'clearly' non-aesthetic criteria, but how do we show this?

These are difficult questions, to which we can give only tentative answers. Frank Sibley $(1959,1965)$ famously argued that aesthetic terms do not have necessary and sufficient conditions for their application, but even if this view is rejected it nevertheless seems that the 'aesthetic' terms employed in science and mathematics are applied with respect to conditions that are far clearer and saliently different to the conditions governing their application in respect of artworks.

For one thing, McAllister and others have given elaborate accounts of the types of simplicity and symmetry appealed to in scientific judgements, and the logic-empirical criteria of theory and proof assessment are much more clear-cut than, say, the criteria for judging the aesthetic merits of artworks. (McAllister 1996, chs. 3 \& 7; Engler 1990)

In this vein, it might also be noted that, unlike the widespread case of disagreement in genuine aesthetic contexts, which can be put down largely to subjective evaluation, the sorts of criteria invoked on behalf of the aesthetic claims made in science and mathematics command virtually universal agreement. ${ }^{9}$ Disagreements over whether a proof is elegant or not, or whether a particular scientific theory displays a virtuous simplicity or symmetry, appear to be rare indeed.

\footnotetext{
${ }^{9}$ See McAllister (1996) for a range of such evidence. For what it's worth, I think his explanation of such agreement and disagreement is plausible, despite the fact that the judgements at issue are not, as he thinks they are, genuinely aesthetic.
} 
Of course, it would be wise not to pin too much on this claim in lieu of detailed empirical evidence, but there do seem to be plausible grounds for holding at least that the normative strength of the putative aesthetic claims made in mathematics and science seems wholly unlike that present in more paradigmatic examples of aesthetic discourse. This, I suggest, indicates that such judgements operate more as epistemic pointers than genuine aesthetic attributions because they have the normative force associated with claims to truth or epistemic warrant.

Certainly, these are not presented as watertight responses to the difficulty of distinguishing between terms used both as aesthetic and epistemic criteria, but the point is that without a formulation of any clear criteria of aesthetic judgement or aesthetic interest, simply appealing to the presence of certain terms in judgements about scientific theories and mathematical proofs, and to the principle of charity of interpretation, is not enough to quell suspicions, allied to the problems so far aired, that such terms may be indicative of epistemic rather than aesthetic value. The judgements and claims at issue are worthy of scepticism because they are too closely correlated with empirical success to warrant being called unequivocally aesthetic, especially in light of the properties appealed to as warrants for them.

Thus, although McAllister is concerned with judgements of 'beauty', and hence with a term which is always used, when used 'properly', to signify aesthetic interest, the properties appealed to as warrants for such judgements - simplicity, unity, symmetry and so on - and the difficulties which beset taking the statements at face value cast no small amount of doubt on the propriety of this usage. If such doubts are justified then it seems that when, for instance, a scientist exclaims that the theory is 'beautiful', she may be doing no more than expressing pleasure in it being a 'good' theory, which is to say empirically successful, and appealing to epistemic properties to support her judgement.

In other words, there are strong grounds for suspecting that what appear to be aesthetic claims may often be, if perhaps not always are, really masked 'epistemic' functional ones and the aesthetic terms at issue - 'beautiful' and 'elegant' and so on - must be being used in a 'quasi', or metaphorical way. Indeed, as we have also seen, and to which McAllister's own study provides ample testimony, it seems that the idea that a theory 
could, for instance, be beautiful but not true is held with some scepticism by many scientists themselves, and the reason for this is obvious if their claims really are epistemically motivated. Moreover, where such cases (and their converse) do happen, as mentioned above, the claims I think tend to support this scepticism because the properties appealed to as evidence of beauty (or lack of it) are more plausibly thought of as being epistemic.

The reception of quantum electrodynamics is a case in point here, where the theory enjoyed tremendous empirical success but struck many physicists as aesthetically displeasing. Dirac wrote, for example, that: 'Recent work...has been very successful...but the resulting theory is an ugly and incomplete one...' where 'incomplete' is clearly not an aesthetic term, and 'ugliness' is cashed out in terms of the ad hoc justification for finite normalization. (McAllister 1996, 94-5) Clearly, these are epistemic criteria, and I suggest that in the case of mathematics one can often simply substitute, under the same arguments, 'truth-apt' for 'epistemic' - the properties appealed to by mathematicians, such as simplicity, symmetry and elegance are all truth-functional properties; or almost all, for these properties might also denote other epistemic virtues in mathematics, for example, 'ease of understanding', 'comprehensibility', 'enlightening' and so on. (Hardy 1940; Osborne 1984)

\section{Objections}

However, one might now raise two important objections. Firstly, am I not simply begging the question that there is some 'paradigmatic' use of aesthetic discourse which does not apply to science and mathematics, but which I have thus far left unspecified? The obvious candidate, apparently, would be discourse specific to the appraisal of art. But then, it will be objected, why should one be less sceptical about the use of supposedly aesthetic discourse in the case of, say, art criticism? What criteria can be given to distinguish pseudo from genuine uses of aesthetic terms in this area?

As I have just hinted, these are very difficult questions, and it is a highly contested area in aesthetics. Of course, one may attempt to outline a solution by providing a clear theory of the aesthetic, such as restricting proper aesthetic judgements, as for example Zangwill 
does, to the expression of the right type of response (sensory), to the right type of (formal) property. (Zangwill 2001, ch. 8.) Or perhaps one might hold, more broadly, that by 'aesthetic property' and 'aesthetic value' is meant any property of an artwork that has artistic value qua work of art. (Gaut, 1998; Carroll, 2000)

Thankfully, it is far beyond the scope of this paper to enter the complex debates about the concept of the 'aesthetic' and to assess the many theories available. All my argument requires, however, is that the debate needs to be entered at some point by those who claim that the judgements made in science and mathematics are genuinely aesthetic because the grounds for scepticism here are, as I have argued, so strong. Moreover, this is so whatever one thinks about how we ought to distinguish genuine from pseudo uses of aesthetic vocabulary in, say, the context of discourse about art.

For whatever one's views about the exact relationship between art and the aesthetic, there is a fundamental difference between science and art that must be explained: it is clear that art and the aesthetic at least seem to be closely connected (somehow) in a way that science and the aesthetic are not (at least not obviously), but more importantly it is not clear that art, unlike science, has any primary purpose such that the aesthetic descriptions used in relation to it could be reduced to descriptions relating to this primary purpose. ${ }^{10}$

Of course, it may be that when someone says, for example of a Monet canvas, 'it is beautiful', this particular judgement is an expression of non-aesthetic interest, such as a desire to own it for purely financial reasons, or because it reminds them of the water lilies proudly grown in their new pond. But in such cases too we conclude in favour of the nonaesthetic nature of the judgements by examining the reasons and properties used to support them. Reduction is a method we can resort to in order to clear up suspicions in our supposedly aesthetic judgements about art no less than in those about science. Yet the lack of an obvious primary (non-aesthetic) purpose at which such reduction aims in the case of art shows, I think, that equivalent warrants for scepticism are lacking here, or at least they require different motivations to those that arise for science.

\footnotetext{
${ }^{10}$ And this claim is of course compatible with the trivial fact that art can have many purposes in addition to that of aesthetic interest; though it is perhaps less clear that these other purposes will pertain to an object qua work of art.
} 
A second putative objection to my argument can be extracted from McAllister's own comprehensive discussion of the relationship between aesthetic judgements and utilitarian performance in the applied arts, where he endeavours to 'allay' the sceptical concerns I might be thought to have aired about this very relationship in science. (McAllister 1996, ch. 9) That is, he argues that aesthetic canons in the applied arts, such as architecture and industrial design, 'respond to utilitarian performance in exactly the way in which aesthetic canons in science do': (142)

'In both domains... the demonstrated practical worth of a work - empirical success in the case of scientific theories, utility in the case of buildings - is capable of reshaping the aesthetic canons on which subsequent work is evaluated...The similarities between the processes by which aesthetic canons develop and are updated in science and applied art should dissipate any scepticism about whether one can properly regard as aesthetic an evaluative canon formed by an inductive response to empirical performance.' (160-1)

Essentially I have no quarrel with this. McAllister makes his case for an aesthetic canon in the applied arts extremely persuasively, but that is simply not the issue. It is not that in such cases aesthetic concerns are necessarily unrelated to considerations of practical or epistemic utility, merely that they are different things, and hence that the relations (if there are any) need to be made clear. What I do take issue with is the idea that considerations of practical utility or epistemic adequacy are themselves aesthetic considerations, not with the idea that they might give rise to some form of aesthetic appreciation.

Moreover, to borrow an argument of Zangwill's, it is not clear that the relationship between aesthetic and functional considerations is in fact the same in the cases of science and the applied arts, for in the latter but not the former 'the aesthetic expression or articulation of function and the actual fulfilling of it can come apart.' (Zangwill 2001, 141) Hence, I do not object to the possibility of an inductive aesthetic canon, but to the idea that McAllister has demonstrated that the canon he discusses clearly involves aesthetic, as opposed to epistemic properties.

In this light it is perhaps worth emphasising the scope of my argument, to make lucid precisely what I am, and what I am not, claiming. To reiterate: we began by taking the claims at face value to see what could be made of the relationship between 'aesthetic' and 
epistemic criteria of theory assessment. Given some of the claims made for the role of the former, the relationship between the two, if they really are different things, looks at worst to be irrational, at best mysterious. On the other hand, if some connection between the two is believed to hold, this connection also looks either equally mysterious, or it appears that the supposedly aesthetic judgements are - given the 'epistemic/truth-functional' nature of scientific theories and mathematical proofs, the epistemic role of the supposedly aesthetic properties appealed to as warrants for putative aesthetic judgements, and granted the plausibility of the rational model of science - most plausibly interpreted as 'masked' epistemic judgements.

My 'positive' sceptical argument has thus been that without clearer or more plausible criteria being provided to distinguish aesthetic and epistemic judgements, and perhaps also to show in what ways and areas they may overlap, there are serious problems with taking the claims at face value that philosophers have overlooked. Hence, in light of the very strong suspicions to which they are prone, there is, I contend, a burden of proof on those who would defend the aesthetic nature of the claims at issue. Where philosophers have attempted to discharge this burden, insufficient or inadequate support has been provided for the criteria selected to defend their aesthetic credentials.

My scepticism, however, is not unassailable, and there is no reason to think that meeting its challenge is impossible. For instance, I have certainly not attempted to demonstrate that all apparent aesthetic judgements in science and mathematics are really masked epistemic claims, nor that it is logically or conceptually impossible to appreciate proofs and theories aesthetically in addition to any other reasons for which we might appreciate them. I am not, that is, arguing that the primarily epistemic activities of science and mathematics cannot also be appreciated aesthetically, merely that if they can it needs to be shown along what axes aesthetic and epistemic appreciation and judgement operate in relation to each other. Aesthetic appreciation and intellectual satisfaction are clearly not necessarily mutually exclusive states, and in order to show otherwise we would indeed need to provide a positive theory and criteria of aesthetic judgement and appreciation. But this is a task which I have explicitly avoided here. 
Instead, I have dwelt on the problem of showing that aesthetic appreciation and epistemic satisfaction are distinct, and hence to avoid collapsing them into each other merely for the sake of keeping the aesthetic appearances of scientific and mathematical claims. This is what the writers we have examined have either failed to accomplish or even to recognize as a problem.

So, although I think that a strong degree of scepticism is warranted about the very nature of the supposedly aesthetic claims at issue, I claim neither a) that this necessarily entails that all, or perhaps even most of the 'aesthetic' claims made in science and mathematics are not genuine, for I do not think this can be readily shown; nor b) that aesthetic and epistemic criteria and judgements need be mutually exclusive; nor c) that it is not possible to appreciate aesthetically the epistemic functioning of theories and proofs. Hence, nothing I have said entails that no aesthetic properties exist which might also, in some sense, function epistemically and which, with a clearer understanding of the relevant conceptual boundaries, we might be able to uncover. It is thus perhaps worth saying a little more, by way of a positive conclusion, about the possibility of overlap between aesthetic and epistemic values. ${ }^{11}$

\section{Concluding thoughts: challenging the sceptic?}

Some notable recent attempts to establish the cognitive, epistemic dimension of some aesthetic properties have been made by Catherine Elgin (2002) and Peter Kosso (2002), both of whom argue that cognitive success, acquiring knowledge and understanding in the sciences, is constituted by properties that are also aesthetic. Thus, Elgin points to the prevalence of metaphor in science, its fundamental cognitive value, and argues that advancements in understanding require reasons not only for thinking that $p$ is true, but for caring whether $p$ is true, and she contends that the salience at issue here is partly an 'aesthetic device'. (Elgin, 2002)

\footnotetext{
${ }^{11}$ It is also perhaps worth noting that I think many of the issues raised here mirror those which have been discussed in the debate concerning the relationship between aesthetic and ethical value. For an overview of the debate see Carroll (2000). For a sceptical view of the purported overlap (in certain cases) between aesthetic and ethical value see Todd (forthcoming).
} 
In similar fashion, Kosso (2002) holds that 'the hallmarks of scientific understanding are similar to an aesthetic feature associated with literature, music, and the visual arts. It is the feature described as coherence, harmony, and inevitability of fit. Aesthetics thus plays an epistemic role in science as an indication of understanding.'(39) Echoing Elgin, Kosso concludes that 'The epistemic significance of beauty is not as a justification for believing a theory is true. It is significant as an indicator of understanding, and in this sense it is a kind of justification for believing a theory is important.'(47) (For related observations see also Root-Bernstein 2002; Lipton 2004, ch. 9; Arnheim 1996).

In respect of these speculations, it is also worth noting that although, on most accounts, aesthetic judgements possess different, weaker normative claims than those made on behalf of scientific knowledge, they are not merely arbitrary. If they are not amenable to truth or correctness in any strong sense, they may still be reckoned to be appropriate or inappropriate, to be fitting or apt, just as the aesthetic properties of objects to which they are responses may be appropriate or fitting. The notion of appropriateness, as many have noted, is one of the hallmarks of aesthetic understanding.

There thus seems to be some continuity in this notion of understanding between art and science, as there does too in features such as seeing connections and patterns, getting the point of a metaphor, appreciating harmony, coherence, order and unity. And not just in science. Hardy, for instance, pointed out the importance of seriousness in mathematics, holding that: 'The seriousness of a mathematical theorem lies, not in its practical consequences, which are usually negligible, but in the significance of the mathematical ideas which it connects'. (Osborne 1984, 294-5) Tim Gowers (2002) concurs with this, arguing that 'Mathematical proofs can provide a similar pleasure with sudden revelations, unexpected yet natural ideas, and intriguing hints that there is more to be discovered.'(51)

It seems to me that these ideas and continuities, including the more nebulous notions of imagination and creativity which play such a central role in the arts and the sciences, are worthy of more thought and deserving of more seriousness than they have hitherto been accorded. Of course it will be evident, given the doubts I have raised in the paper, that much work needs to be done to sort out in what ways these various properties and concepts - understanding, seriousness, fit, harmony and so on - might be identified as 
aesthetic, and how far such continuities can be stretched without conceptual confusion arising.

Yet, given how loose and unclear our pre-theoretical notion of the 'aesthetic' is, how highly disputed the philosophical attempts to define the concept have been, and how little work has been done on the relationship between aesthetic and epistemic value, there is nothing, I think, to preclude the possibility that some aspects of aesthetic value may possess a cognitive function and that conceptual boundaries are not as rigid as they might at first appear. Indeed, it may be that if we shift our emphasis from talk of 'properties' to talk of 'evaluations' that it will become easier to see how we may evaluate, for example, epistemic success from an aesthetic point of view, and perhaps conversely evaluate various aesthetic features and phenomena for their epistemic value.

One way of accomplishing this might be to equate aesthetic value with the appreciation of the appropriateness of the relation between form and content, thereby explaining the aesthetic value of proofs and theories in terms of the way in which their epistemic content is conveyed; elegantly, simply, symmetrically, beautifully and so on. A different approach might be, say, to take scientific and mathematical objects as paradigmatic aesthetic objects, and the pleasure involved in doing science and mathematics to be paradigmatically aesthetic pleasure, as some $18^{\text {th }}$ century writers did. Although there is no space to detail these views here, if it can be shown to be possible that aesthetic values can have epistemic functions, and epistemic values can be appreciated aesthetically, there may emerge some potentially important implications for aesthetics, the philosophy of science, and epistemology more generally.

\section{Acknowledgments}

I would like to thank Alix Cohen, Rachel Cooper, James McAllister, and audiences at Lancaster University and University College Cork, where this work was presented in earlier versions, for their encouragement and help in clarifying my ideas. 


\section{Bibliography}

Arnheim, R. (1996) Beauty as Suitability, Journal of Aesthetics and Art Criticism, 54, pp. 251-3.

Carroll, N. (2000) Art and Ethical Criticism: An Overview of Recent Directions of Research, Ethics, 110, pp. 350-87.

Davies, D. (1998) McAllister's aesthetics in science: a critical notice, International Studies in the Philosophy of Science, 12, pp. 25-31.

Elgin, C. (2002) Art in the Advancement of Understanding, American Philosophical Quarterly, 39, pp. 1-12.

Gaut, B. (1998) The Ethical Criticism of Art, in: J. Levinson (Ed.) Aesthetics and Ethics: Essays at the Intersection (Cambridge, Cambridge University Press), pp. 18297.

Gowers, T. (2002) Mathematics: A Very Short Introduction (Oxford, Oxford University Press).

Hardy, G. (1940) A Mathematician's Apology (Cambridge, Cambridge University Press).

Harré, R. (1958) Quasi-Aesthetic Appraisals, Philosophy, 33, pp. 132-7.

Engler, G. (1990) Aesthetics in Science and Art, British Journal of Aesthetics, 30, pp. 24-33.

Kivy, P. (1991) Science and Aesthetic Appreciation, Midwest Studies in Philosophy, 16, pp. 180-95.

Kosso, P. (2002) The Omniscienter: beauty and scientific understanding, International Studies in the Philosophy of Science, 16, pp. 39-48

Lipton, P. (2004) Inference to the Best Explanation (London, Routledge).

McAllister, J. (1991) Scientists' Aesthetic Judgements, British Journal of Aesthetics, 31, pp. 332-41.

McAllister, J. (1996) Beauty and Revolution in Science (New York, Cornell University Press).

McAllister, J. (2005) Mathematical Beauty and the Evolution of the Standards of Mathematical Proof, in: M. Emmer (Ed.) The Visual Mind II (Massachusetts: MIT Press), pp. 15-34.

Osborne, H. (1984) Mathematical Beauty and Physical Science, British Journal of Aesthetics, 24, pp. 291-300. 
Penrose, R. (1974) The Role of Aesthetics in Pure and Applied Mathematical Research, Bulletin of the Institute of Mathematics and its Applications, 10, pp. 26671.

Root-Bernstein, R. (2002) Aesthetic Cognition, International Studies in the Philosophy of Science, 16, pp. 61-77.

Sibley, F. (1959) Aesthetic Concepts, reprinted in: J. Benson, B. Redfern, J. Cox (Eds.) Approach to Aesthetics (Oxford: Clarendon Press), pp. 1-23.

Sibley, F. (1965) Aesthetic and Non-aesthetic, reprinted in: J. Benson, B. Redfern, J. Cox (Eds.) Approach to Aesthetics (Oxford: Clarendon Press), pp. 33-51.

Stolnitz, J (1961) On the origins of "aesthetic disinterestedness", Journal of Aesthetics and Art Criticism, 20, pp. 131-43.

Todd, C. (forthcoming) Aesthetic, Ethical, and Cognitive Value, South African Journal of Philosophy.

Zangwill, N. (2001) The Metaphysics of Beauty (New York: Cornell University Press). 